\title{
Study on the Development of Rural Tourism in Xinjiang
}

\author{
Gulzar Abdursul
}

The Tourism College of Xinjiang University, Xinjiang, 830001, PRC, China

\begin{abstract}
Keywords: rural tourism; development; strategy.
\end{abstract}
\begin{abstract}
With the strengthening of China's economic strength, the spiritual pursuit of Chinese people is getting higher and higher. The spiritual emptiness after physiological needs are met should be slowly calmed in nature. This spiritual pursuit is a kind of emotional cultivation, which is also intermingled with the tourism development strategy in our country. The development of tourism in Xinjiang is in the situation with both opportunities and crises. What it is in face with are not only severe challenges but also important opportunities and favorable conditions. The beautiful Xinjiang has very rich tourist resources characterized by national customs with distinctive regional characteristics. It has not only time-honored cultural relics but also natural landscapes in different shapes. The unique national culture and rich tourist resources make the tourism of Xinjiang show a very good development trend. With the continuous development of tourism in this area, it has become an important leading industry here and plays a vital role in the development of regional economy.
\end{abstract}

\section{Introduction}

The starting of rural tourism in China is much later than that in foreign countries. It started at the end of the 70s of the last century. With the continuous development of the economy and society, the gradual improvement of people's living standard promotes the improvement of people's consumption level and their concept has also changed greatly. Besides, the golden week for tourism every year has further promoted the rapid development of rural tourism. Rural tourism has shown a very good trend of development in recent years. China' $s$ tourism industry will go through the golden period of tourism between 2010 and 2020. Therefore, the tourism industry should be vigorously developed in accordance with the reality of the region.

\section{The Necessity and Urgency of Developing Rural Tourism in Xinjiang}

\subsection{The Necessity of Developing Rural Tourism in Xinjiang}

As far as the current rural tourism in Xinjiang, its development level is still relatively low and much worse compared with some advanced areas in China. Before the 1990s, many scenic spots in this area were still not developed effectively, and the slow development of transportation caused great hindrance to the local tourism industry, so that its development was relatively slow. After that, nationwide tourism industry welcomed a good development trend with the great improvement of economic situation. Thanks to the two times of conferences on economic work conducted by the central government in Xinjiang, this area has made rapid economic development in recent years and its related institutional improvement has been gradually improved. At the same time, people are getting increasingly wealthier and the level of their material life is also increasingly improving. The rapid development of transportation industry and the development and construction of various scenic spots have also greatly promoted the development of tourism in this area. As a result, rural tourism is becoming more and more popular and it has become an important tourist destination for travel.

Xinjiang has rich natural resources and folk custom resources as well as a variety of dwellings with distinctive ethnic characteristics, which can be used for tourists to visit. However, from the perspective of overall analysis, the rural tourism in Xinjiang is still in relatively slow development and confronted with numerous difficulties. Therefore, it is becoming more and more important to study the problem of rural tourism in this area. Only by taking pertinent measures based on these problems can the local tourism industry be promoted continuously. 


\subsection{The Urgency of Developing Rural Tourism in Xinjiang}

Nur Bekri once pointed out in the Work Conference on the Xinjiang Uygur Autonomous Region Tourism that, tourism has become one of competitive industries with the most development potential and market prospects in national economy in Xinjiang. The high relevance and wide coverage of tourism industry makes itself become an industry with great development potential and obvious driving effect in Xinjiang. To develop tourism vigorously is not only an important part of expanding domestic demand, but also an important "engine” for promoting industrial structure adjustment and transformation of economic growth mode. Furthermore, it is also an important window for the harmonious, stable and prosperous development of Xinjiang. It is necessary to give full play to the role of tourism in adjusting the economic structure and changing the way of economic development. It is supposed to play its role in ensuring growth, expanding domestic demand and promoting the development of the third industry. It can also exercise a strong influence on protecting employment and people's livelihood. The government should vigorously implement a strategy of competitive products, give full play to the effect of famous tourism brands, increase policy support, strive to promote the construction of tourism infrastructure and give full play to the "window" role of tourism and rebuild the harmonious and stable image of Xinjiang.

$\mathrm{Hu}$ Wei, the vice president of Xinjiang Uygur Autonomous Region, stressed when he presided over the meeting that, special attention should be given to integrate tourism resources to enhance the competitiveness of the tourism in Xinjiang, speed up the integration of tourism-related industries to accelerate the integration of tourism industry chain and tourism resources; and it is also deserved to adhere to the strategy of large enterprises and groups, aiming at introducing a number of strategic investors.

\section{The Status Quo of Rural Tourism Development in Xinjiang}

Nowadays, rural tourism in many areas in China has been well developed, but Xinjiang develops relatively slowly due to various reasons. Many tourism resources in Xinjiang had not yet been effectively developed before the 1990s. The lagging development of transportation and accommodation problems made the tourism industry stagnant and lack sufficient development potential. After the 1990s, the economic situation in China has been greatly improved, and the economy throughout the country shows a good development momentum, so does it in Xinjiang. The economy here has developed by leaps and bounds; the related system construction is increasingly perfected; people's lives become better and better and economic material life is greatly improved. At the same time, various scenic spots have begun to carry out development and construction, and the rapid development of the transportation industry has resulted in better and better living conditions. Many residents choose to travel in Xinjiang and the number of tourists also increases year by year, injecting new vitality into rural tourism in Xinjiang. Tourists can enjoy rich natural resources and folk custom resources as well as a variety of dwellings with distinctive regional characteristics in Xinjiang. However, in general, the development of rural tourism in Xinjiang is still relatively slow and faces many difficulties. Therefore, it has become an increasingly important thing to study the problem of rural tourism in this area. Only by taking pertinent measures based on these problems can the local tourism industry be promoted continuously.

\section{The Problems in the Rural Tourism Development in Xinjiang}

Nowadays, China's tourism industry, including the rural tourism, is showing a very good momentum of development and has broad development prospects. Rural tourism is an important part of the tourism industry and occupies a very important position in it. It is also an important component of tourism industry in Xinjiang. However, the lack of scientific planned development in the development process has resulted in uneven spot scales of rural tourism and quite low service level, which have had a great impact on the development of the local rural tourism. Through comprehensive analysis, the problems existing in rural tourism in Xinjiang are summarized as follows: 


\subsection{Lack of Scientific Operation Philosophy}

Xinjiang rural tourism needs the support of superior tourism products and good services to satisfy tourists' psychological expectations. But some operators only pay attention to immediate peanuts and lack the scientific management philosophy. The tourism products they choose are often too vulgar to be able to coordinate with the original intention of developing rural tourism in Xinjiang and also cannot fully reflect the local rural characteristics. Many ethnic cultures with strong regional characteristics have not been effectively excavated, and the exploration and implementation of relevant tourism products have not been carried out according to tourists' age, which has seriously affected the development of local rural tourism.

\subsection{Too Single Tourism Products}

Based on the analysis of the rural tourism in Xinjiang, it is easy to find that many tourism projects are nearly the same and lack a sense of novelty. It is difficult for single tourism products to fully embody local characteristics, so that the quality and taste of products cannot be improved. As far as the current rural tourism in Xinjiang is concerned, the main products are still natural scenery and rural leisure, without any novelty. Therefore, many tourists are unwilling to participate because of the big gap between the actual situation and their travel expectations.

\subsection{No Overall Scientific Planning}

With the continuous development of the economy, the tourism industry in Xinjiang has also been greatly improved. At the same time, the development of the tourism industry has also stimulated the local economy and has huge impacts on the dual-structure of urban and rural areas. Local governments are also gaining a lot in the process of developing rural tourism, and they are vigorous in developing rural tourism. Rural tourist spots have spread all over the country now. However, due to the lack of scientific and effective planning, these spots are not only different in scale but also do not have a unified service level. Due to the lack of construction funds and scientific appraisal for local rural tourism, the quality of local rural tourist spots is in urgent need of improvement while the number grows rapidly during the development process. Moreover, over-emphasis on immediate interests, lack of understanding of the status of developing rural tourism and neglect of sustainable development leads to the fact that there are too many artificial factors in rural tourism construction. Many villages are characterized by rapid urbanization, which has caused great damage to the local natural scenery. This is extremely detrimental to the sustainable development of local rural tourism.

\subsection{Shortage of Professional Tourism Talents}

Xinjiang is located in the northwestern region of China. It is geographically remote and belongs to the underdeveloped regions of China. The talent cultivation here is still somewhat lagging compared with developed regions in China. At present, rural tourism attractions in Xinjiang are mainly developed by local farmers, without professional tourism management personnel and related perfect personnel training system. Furthermore, no targeted scientific training was given these famers when they developed rural tourism. The lack of professional personnel has formed a major constraint on the development of local tourism and has become a major problem for this industry here.

\section{The Strategies to Develop and Construct Rural Tourism}

\subsection{To Renew Ideas and Fully Tap Local Tourist Products}

Xinjiang is rich in tourism resources. These resources should be well utilized and fully tapped to provide tourists with cultural tourism products that are rich in culture and without losing local characteristics. Renewing the concept of tourism management must be considered in the long run. Operators cannot only focus on the immediate small profits but should completely abandon those vulgar tourism products and create rural tourism with local characteristics based on the sustainable development of the ecology, economy and society. At the same time, rural tourism carries a lot of cultural contents. Therefore, in the process of developing local rural tourism in Xinjiang, it is necessary to rely on natural scenery resources to fully tap the local folk customs and cultural monuments to launch rural tourism products embodied local culture. The rural tourism development in this way can not only effectively protect the local traditional culture but can also greatly promote 
the local ecology. Precisely because of the increasing enhancement of modern people's environmental consciousness, they are more interested in traveling in natural scenery, and thus the integration of tourism and culture will be sought after by more and more people. In this sense, the creation of rural tourism with local cultural characteristics by well combining local culture with tourism products not only can further expand the local cultural connotation, but also is very beneficial to the development of local rural tourism.

\subsection{To Vigorously Tap the Tourism Products and Enrich Local Tourism}

The development of tourism products is very significant for the development of tourism. And now all parts of the country are building their own tourism products, and the competition is becoming more and more severe. In this context, rural tourism in Xinjiang must seek new breakthroughs and strive to create local tourism products that are in line with the local characteristics and add value to local rural tourism. Therefore, unified management and reasonable planning should be implemented to design tourism products scientifically and make overall coordination, so as to achieve rational allocation of tourism resources. At the same time, it is needed to further enhance the capability of tourism service to attract large numbers of tourists from different places to Xinjiang, so as to promote the sustainable development of local rural tourism.

\subsection{To Promote the Diversification of Rural Tourism Products}

In order to promote the continuous development of rural tourism in Xinjiang, local tourism products should be diversified. Agricultural eco-tourism development and rural eco-tourism construction can be used to further expand the eco-tourism in mountainous areas and forestry eco-tourism in Xinjiang. It is also feasible to create ecological tourism in river and lake regions by renovating them. In this process, attention can be paid to full exploitation of the folk culture forms with profound local features such as Xinjiang song and dance, drama and acrobatics, so as to develop diversified cultural products.

\subsection{To Cultivate and Promote Tourism Professionals}

It is feasible to rely on the local colleges and universities to enhance the training of tourism professionals and promote their quality. It is also needed to provide professional training for farmers who develop rural tourism to improve their overall quality, so as to promote the upgrading of rural tourism to recreational tourism.

\section{Conclusion}

The rise and development of rural tourism plays a great role in promoting the development of local society and economy. Based on the comprehensive and in-depth investigation and research on the development of rural tourism in Xinjiang in recent years, the author analyzed the development status of rural tourism there, found out problems in its development and put forward constructive countermeasures and suggestions. The tourism industry has played an indelible role in Xinjiang. No matter where it is developed, tourism should be developed according to local conditions.

\section{References}

[1]. Li Bowen. A Research Overview of Urban Tourism at Home and Abroad [J]. Tourism Tribune, 2010, (6): 88-90

[2]. Li Junfeng. Discussion on the Development Strategy of Rural Tourism in Zhengzhou Based on Residents' Travel Consumption Preference [J]. Journal of Anhui Normal University,2010, (6):577-579

[3]. Huang Chun. Problem Analysis of the Integration of Agro-tourism and Cultural Development in China's Rural Areas [J]. Charming China, 2014, (13): 15-16

[4]. Xu Xingbin, Jiao Li, Wang Ningxia, et al. The Status Quo of Tourism Human Resources in Xinjiang and Its Development Strategies [J]. Economic Research Guide, 2011, (23): 92-93. 